CARCINOMA OF THE STOMACH, WITH SOFTENED AND HYPERTROPHIED LIVER.

By W. Henderson, M.D., Edinburgh.

$I_{T}$ is not from anything new in the patho. $\log y$ of the following case that $I$ send it, but from the peculiar arrangement of the parts at the pyloric orifice, it is rendered curious and interesting:-

Mr. Wilson, ætat. 45, an intelligent, active man, with white-pasty complexion and contracted features, suffered six summers ago from a smart attack of jaundice, which returned the two following summers: there was an interregnum of one year of tolerable good health; about the termination of that year he suffered much from dyspepsia and uneasiness across the epigastric region; six months ago he had a smart attack of hæmatemesis, and three months afterwards a second, though slight, attack, and almost constant uneasiness in the region of the liver or stomach; he never complained of great pain in both places at the same time; he also suffered much latterly from distention after eating; he had considerable thirst and frequent vomiting of a chocolate-coloured fluid, with coffee-looking grounds throughout it.

Dissection.-The liver was double its usual size, of a light cinnamon colour, very soft, and easily lacerable ; in lifting it from its position the point of the finger penetrated its substance, otherwise healthy.

The stomach was enormously large, hypertrophied, and inflated; it filled the whole upper part of the abdomen, pushing the left lobe of the liver and diaphragm high into the chest. On opening it a considerable quantity of gas escaped; it contained half a gallon of chocolate-coloured fluid; the inner membrane was coated over with a great -abundance of ropy mucus, with sooty-coloured streaks interspersed through it; it was capable of holding half a gallon more of fluid; its blood-vessels were much enlarged; there was an extensive deposition of scirrhous matter in the pyloric orifice; in the upper third of the orifice the scirrhoid deposit was half an inch in thickness; in the other two-thirds, or depending portion, one inch and a half in thickness; the thickened orifice made a complete twist or screw round upon itself from the left to the right in the exact manner of a bottle screw, by which the floor of the orifice was raised against the ontlet in the manner of a valve, thus very much impeding direct exit from the viscus, the channel or passage being through the sinuosity of the screw; at the base or rise of the twist there were two small, minutely injected points. The kidneys were large, soft, and contained fluid blood; the heart, perhaps, larger than usual, was very flaccid; right ventricle empty; left contained a long fibrinous clot, which floated up the superior cava. The lungs were healthy, but studded over with black spots, not an uncommon appearance in persons of Mr. Wilson's age. A sister and he were the only survivors of a large family, all of whom died of consumption at various ages.

Corstorphine, Edinburgh, July 29, 1842.

\section{PLACENTAL PRESENTATION}

WITH

\section{FATAL TERMINATION.}

\section{To the Editor of THE LANCET.}

SIR,-After some reflection I have arrived at the conclusion that a faithful record of all unsuccessful or unfortunate cases, though destitute of a signature, would prove almost as beneficial to practitioners, and mankind in general, as the more prevalent custom of selecting those marvellous cases only where diagnosis, prognosis, result, and treatment kiss each other so happily, and to which are invariably appended the full name, address, qualification, \&c., of the discriminating anthor. Should you deem this case of placental presentation of sufficient interest to your numerous readers to warrant its insertion in your valuable Journal, it is very much at your service, and I beg to subscribe myself y our humble servant,

A General Practitioner.

\section{London, July 21, 1842.}

I was desired to visit Mrs. W., ætat. 36 , about five o'clock p.m., on the 9th inst., and found that a midwife had been in attendance occasionally during the preceding week. She had suffered from hæmorrhage, at intervals, for the last ten days, for which she had kept in bed and applied cold applications. The countenance was exsangueous; pulse rather quick and soft; no appearance of distress or faintness; the hæmorrhage did not appear to be of any great extent; the pains of a grind. ing character and slight, with long intervals ; none occurred during my visit. On making an examination per vaginam, I discovered what appeared to be a placental presentation at the extremity of a mass of coagula, with the os uteri dilated just sufficient to admit the top of the forefinger. I did not disturb the coagula, but prescribed an acidulated mixture, enjoined the recumbent position and the room to be kept cool, applied cold applications, and desired I might be sent for instantly on the re-appearance of flooding or accession of labour-pains.

I lost no time in communicating to a medical friend of considerable experience what $I$ apprehended the case to be, who promised to be in readiness should his assistance be re. quired. 